\title{
RANCANG BANGUN APLIKASI MANAJEMEN GUDANG SUKU CADANG ALAT BERAT PNJ
}

\author{
Abdul Azis Abdillah', Muhammad Toby Adigunanugraha, Ivana Bianca \\ Prodi Alat Berat, Jurusan Teknik Mesin, Politeknik Negeri Jakarta \\ Jalan Prof. Dr. G. A. Siwabessy, Kampus UI, Depok 16425 \\ e-mail: abdul.azis.a@mesin.pnj.ac.id
}

\begin{abstract}
Heavy Equipment Study Program, Jakarta State Polytechnic, has a warehouse that aims to store spare parts. These spare parts are used to meet the practical needs of students when lectures take place every semester. During this time, to lend and report spare parts, heavy equipment warehouse technicians still use forms and spare parts cards. This method is less effective when the stakeholders such as the Head of Workshop and Head of Study Program want to know the amount of spare parts stock that is still owned by the warehouse or data warehouse cannot be seen in real time. From these problems, the warehouse needs a way to speed up the process. One method that can be used to overcome this problem is to create a web-based system or application that can carry out an inventory, record, process, and report the spare parts data contained in the heavy equipment warehouse. This writing aims to design and build warehouse management applications for heavy equipment spare parts. So, with this web-based application, stake holders can view reports from the warehouse with the right target, accurate, and efficient.
\end{abstract}

Key words: Management, Warehouse, Web-based application

\begin{abstract}
ABSTRAK
Program Studi Alat Berat Politeknik Negeri Jakarta, memiliki sebuah gudang atau warehouse yang bertujuan untuk menyimpan suku cadang. Suku cadang ini digunakan untuk memenuhi kebutuhan praktek mahasiswa saat perkuliahan berlangsung pada setiap semester. Selama ini, untuk melakukan peminjaman dan pelaporan suku cadang, teknisi gudang alat berat masih menggunakan formulir dan kartu suku cadang. Cara ini kurang efektif disaat para stake holder seperti Kepala Bengkel dan Kepala Program Studi ingin mengetahui jumlah stock suku cadang yang masih dimiliki oleh gudang atau data gudang belum dapat dilihat secara real time. Dari permasalahan tersebut, gudang memerlukan suatu cara untuk dapat mempercepat proses tersebut. Salah satu cara yang dapat digunakan untuk mengatasi masalah tersebut adalah dengan membuat sebuah sistem atau aplikasi berbasis web yang dapat melakukan inventarisasi, pencatatan, pengolahan, dan pelaporan data suku cadang yang terdapat pada gudang alat berat. Penulisan ini bertujuan untuk melakukan rancang bangun aplikasi manajemen gudang suku cadang alat berat pnj. Sehingga, dengan adanya Aplikasi berbasis web ini, stake holder dapat melihat laporan dari gudang dengan tepat sasaran, akurat, dan efisien.
\end{abstract}

Kata kunci: Manajemen, Warehouse, Sistem Informasi

\section{PENDAHULUAN}

Suku cadang atau sparepart (Indrajit, 2005) merupakan suatu alat yang mendukung pengadaan barang untuk keperluan peralatan yang digunakan dalam proses produksi. Suku cadang mempunyai peranan yang cukup besar dalam serangkaian aktivitas perusahaan. Hal ini dikarenakan suku cadang merupakan salah satu faktor utama yang menentukan jalannya proses produksi pada suatu perusahaan.
Faktor lain yang berkaitan dengan suku cadang adalah penyimpanan. Sistem penyimpanan suku cadang memegang peranan penting yang berpengaruh terhadap efisiensi waktu produksi. Tempat penyimpanan suku cadang sementara biasa disebut sebagai gudang (Lambert, 2001).

Gudang merupakan bagian dari sistem logistik perusahaan yang digunakan untuk menyimpan produk-produk (bahan baku, suku cadang, dan barang jadi). Selain itu gudang juga diperlukan 
sebagai penyedia informasi kepada manajemen mengenai status, kondisi dan disposisi dari komponen yang disimpan. Pengelolaan yang baik terhadap gudang saat diperlukan untuk menunjang proses produksi.

Suku cadang yang terdapat pada gudang Program Studi Alat Berat Politeknik Negeri Jakarta (PNJ) tidak bersifat baru namun suku cadang tersebut merupakan suku cadang yang sudah tidak digunakan atau hibah dari PT Trakindo Utama (PT TU) yang kondisinya masih dapat dipergunakan kembali. Ada dua jenis suku cadang yaitu untuk digunakan sebagai pengganti komponen yang mengalami kerusakan dan yang digunakan hanya sebagai bahan ajar praktikum, suku cadang jenis ini bersifat peminjaman harus dikembalikan ke gudang untuk digunakan kembali ketika hendak digunakan praktikum di lain waktu, kedua jenis suku cadang yang penting untuk menunjang kegiatan praktikum.

Akan tetapi, berdasarkan hasil observasi yang dilakukan oleh penulis, kondisi pendataan terhadap suku cadang yang ada di gudang Alat Berat PNJ masih belum tertata dengan baik. Sehingga saat mahasiswa memerlukan suku cadang ketika praktikum menjadi terhambat karena memerlukan waktu lebih dalam mencarinya. Selain itu pula, disaat ada audit oleh stake holder pengelola gudang seringkali kesulitan menyediakan bukti-bukti penggunaan dan peminjaman dikarenakan masih menggunakan metode manual seperti formulir peminjaman dan kartu suku cadang.

Pada tulisan ini penulis mencoba menerapkan penggunaan sistem informasi untuk mengatasi masalah diatas. Beberapa penelitian terkait manajemen gudang menggunakan sistem informasi antara lain dilakukan oleh Agusvianto (2017), Leopatria M. (2013) dan Sudana (2007). Semua penelitian tersebut memberikan sebuah kesimpulan yang relatif sama yaitu keefektifan dan keefisienan manajemen gudang menjadi lebih meningkat dari sebelumnya.

Berdasarkan latar belakang di atas, maka tujuan dari penulisan ini adalah untuk melakukan rancang bangun aplikasi manajemen gudang suku cadang pada program studi alat berat Politeknik Negeri Jakarta.

\section{METODE PENELITIAN}

Metode penelitian yang digunakan pada penelitian ini terdiri dari delapan tahap, yaitu:

1. Membuat sistem requirement

2. Menentukan entitas terkait

3. Membuat DFD (Data Flow Diagram, Gambar 1)

4. Menentukan atribut setiap entitas (Gambar 2)

5. Membuat Database dan Relasinya (Gambar 3)

6. Merancang Tampilan Antarmuka

7. Pembuatan Program

8. Testing

Alat dan bahan yang dibutuhkan pada penelitian ini berupa hardware dan software. Berikut daftar lengkap alat dan bahan yang dibutuhkan (1) Hardware : Notebook Asus A43SV (2) Software : OS Windows 7 Ultimate 64bit, XAMPP 1.7.3, Adobe Dreamweaver CC 2015, Browser (Google Chrome)

\section{HASIL dan PEMBAHASAN}

Pada bagian ini dijelaskan mengenai tahap-tahap pembuatan aplikasi dan implementasinya.

\section{Implementasi Aplikasi}

Aplikasi ini memuat 2 bagian utama yaitu akun admin sebagai pusat penggelolaan data dan akun user sebagai aplikasi yang digunakan mahasiswa untuk melakukan aktivitas peminjaman dan pengembalian barang. 


\begin{abstract}
Akun Admin
Akun admin dibuat oleh sistem dan hanya orang tertentu yang dapat dijadikan admin seperti karyawan gudang, akun ini digunakan untuk membuat atau mendaftarkan pengguna lainnya agar dapat menggunakan aplikasi tersebut. admin dapat mengelola data pengguna, data barang, data barang yang sedang dipinjam serta data arsip. Contoh akun admin dapat dilihat pada gambar 5 .
\end{abstract}

\section{Admin Panel}

Admin panel atau menu admin berisikan menu-menu yang dapat dikelola oleh admin, seperti beranda, data user, data barang, data barang yang sedang dipinjam dan arsip. Dalam hal ini admin dapat menambahkan dan merubah data yang ada. Contoh admin panel dapat dilihat pada gambar 5 .

\section{Menu beranda}

Pada menu ini digunakan untuk memberikan informasi terbaru yang diterbitkan oleh admin kepada pengguna, informasi yang diberikan oleh admin dapat dilihat di menu beranda pada akun pengguna. Contoh menu beranda dapat dilihat pada gambar 5.

\section{Menu Data User}

Pada menu ini memuat akun mahasiswa yang telah terdaftar pada aplikasi, saat ada mahasiswa yang hendak menggunakan aplikasi tetapi belum terdaftarkan, maka admin berwenang untuk mendaftarkan akun tersebut dengan perintah "Tambah Data" diperlukan Nomor Induk Mahasiswa, nama, dan password untuk didaftarkan agar mahasiswa dapat masuk ke dalam aplikasi. Admin yang mengelola pengaturan pertama kali akun untuk keperluan mengubah atau menghapus data akun yang ada. Contoh menu data user dapat dilihat pada gambar 5 .

\section{Menu Data Barang}

Pada menu ini berisikan data barang yang tersedia di gudang suku cadang, data yang ada dapat diubah dan disesuaikan dengan kondisi yang ada seperti perubahan lokasi dan jumlah dengan perintah pengaturan edit atau hapus. Apabila terjadi penambahan barang yang tidak lebih dari satu item namun jumlahnya lebih dari satu maka admin dapat menambahkan barang dengan perintah “Tambah Data”, tetapi jika penambahan lebih dari satu item maka dapat menambahkannya melalui database. Contoh menu data barang dapat dilihat pada gambar gambar 5 .

\section{Menu Data Pinjaman}

Pada menu ini berisikan data barang yang sedang dipinjam oleh mahasiswa, admin dapat mengetahui barang apa saja yang sedang dipinjam oleh mahasiswa dengan melihat Nomor Induk Mahasiswa, nama, tanggal peminjaman sejak barang tersebut dipinjam dan nomor pinjam sebagai nomor traksaksi atau nomor aktivitas peminjaman. Apabila mahasiswa belum mengembalikan barang, maka data tersebut akan tetap ada pada data pinjaman, namun jika mahasiswa telah mengembalikan barang yang telah dipinjamnya maka data yang ada akan otomatis hilang dan masuk kedalam menu arsip. Contoh menu data pinjaman dapat dilihat pada gambar 5.

\section{Menu Arsip}

Arsip berisikan data-data siapa saja yang telah meminjam dan mengembalikan barang, data barang yang sedang dipinjam pada menu data pinjaman dan telah dikembalikan akan otomatis terhapus sehingga data tersebut akan menjadi arsip. Data arsip dapat digunakan untuk proses pengecekan kondisi yang ada dalam sistem dengan kondisi aktual pada gudang, memuat informasi lengkap serta tanggal sejak peminjam hingga tanggal pengembalian. Contoh menu arsip dapat dilihat pada gambar 5 .

\section{Menu Ganti Password}

Pada menu ganti password bertujuan untuk menjaga kerahasiaan data yang terdapat dalam akun admin, sehingga 
tidak ada orang lain yang menyalahgunakan, hanya admin yang bersangkutan yang dapat mengganti password lama yang dibuat oleh sistem dengan password baru sesuai keinginan admin tersebut. Contoh menu ganti password dapat dilihat pada gambar 5 .

\section{Akun User}

Akun user atau mahasiswa adalah akun pada aplikasi yang digunakan untuk meminjam dan mengembalikan barang yang ada pada gudang, akun ini dibuat dan didaftarkan oleh admin yang berwenang, mahasiswa perlu menyerahkan kartu tanda mahasiswa sebagai syarat pendaftaran untuk dicatat Nomor Induk Mahasiswa, nama mahasiswa serta password awal untuk masuk ke dalam aplikasi. Contoh akun user dapat dilihat pada gambar 6 .

\section{User Panel}

User panel atau menu pengguna berisikan menu-menu yang ada pada akun pengguna seperti beranda, data barang, form list dan ganti password. Menu yang tersedia digunakan untuk melakukan aktivitas peminjaman dan pengembalian barang. Contoh user panel dapat dilihat pada gambar 6 .

\section{Menu Data Barang}

Menu ini berisikan data barang yang tersedia pada gudang, memuat informasi mengenai nama barang, lokasi dimana barang ditempatkan, jumlah barang yang tersedia dan kode barang. Mahasiswa dapat mempercepat pencarian barang dengan memasukkan nama barang dikolom pencarian untuk menyortir barang tersebut, jika pencarian barang telah didapatkan maka dapat menekan perintah "pinjam" untuk memasukkan jumlah barang yang ingin dipinjam sesuai kebutuhan dan jumlah barang yang tersedia akan otomatis berkurang. Mahasiswa dapat meminjam lebih dari satu barang dengan cara yang sama, barang-barang yang ingin dipinjam tersebut akan masuk ke dalam menu form list untuk dicatat. Contoh menu data barang dapat dilihat pada gambar 6.

\section{Menu Form List}

Pada menu ini terdapat 2 form list, yaitu form list peminjaman barang dan form list barang yang sedang dipinjam. Form list peminjaman barang ini berisikan kumpulan data barang yang ingin dipinjam oleh mahasiswa yang telah dicari pada menu data barang, dalam daftar ini mahasiswa dapat melihat kembali daftar barang beserta jumlahnya, apabila terjadi perubahan terhadap barang yang ingin dipinjam maka dapat dibatalkan dengan perintah pengaturan cancel atau tanda silang untuk membatalkan. Setelah semua data barang lengkap maka mahasiswa dapat menghubungi admin untuk meminta diambilkan barang tersebut secara lengkap dan menekan perintah "pickup" sebagai tanda bahwa barang tersebut telah lengkap untuk dipinjam.

Barang yang telah di pickup pada form list peminjaman barang akan masuk ke dalam form list barang yang sedang dipinjam, jika terjadi lebih dari satu kali peminjaman atau pickup dan barang sebelumnya belum dikembalikan maka data barang peminjaman tersebut akan terkumpul pada list ini dengan nomor pinjam dan waktu yang berbeda. List ini terkoneksi dengan menu data pinjaman pada akun admin sehingga admin mengetahui barang apa saja yang sedang dipinjam dan belum dikembalikan oleh mahasiswa, jika mahasiswa telah selesai menggunakan lalu ingin mengembalikannya maka dapat menekan perintah "kembalikan" untuk mengembalikan semua barang yang ada dalam form list barang yang sedang dipinjam dan secara otomatis data pinjaman dalam akun admin akan terhapus dan masuk dalam menu arsip. Contoh menu form list dapat dilihat pada gambar 6 . 


\section{KESIMPULAN}

Berdasarkan hasil perancangan dan percobaan pada aplikasi yang telah dilakukan pada gudang suku cadang teknik alat berat maka diperoleh hasil sebagai berikut, yaitu sistem ini merupakan suatu aplikasi pada gudang alat berat yang berfungsi sistem inventori untuk melakukan pencatatan keluar masuk barang oleh teknisi gudang alat berat PNJ. Selain itu, pencatatan dapat dilakukan dengan lebih terstruktur sehingga dapat memberikan bantuan dalam hal efisiensi waktu dalam kegiatan pencatatan dan penyusunan data suku cadang. Dengan adanya aplikasi berbasis web ini dapat mempermudah dalam hal pembuatan laporan keluar masuknya barang dari gudang secara tepat, akurat dan tepat sasaran.

\section{DAFTAR PUSTAKA}

[1] Agusvianto, Hendra. 2017. Sistem Informasi Inventori Gudang Untuk Mengontrol Persediaan Barang Pada Gudang Studi Kasus : PT.Alaisys Sidoarjo. JIEET. Vol 01, No. 01.

[2] Indrajit, R.E. Djokopranoto, R. 2005 Manajemen Persediaan, Barang Umum dan Suku Cadang untuk Keperluan Pemeliharaan, Perbaikan dan Operasi. Yogyakarta: Grasindo.

[3] Leopatria, M., Palit, H. C. 2013. Perancangan Sistem Manajemen Gudang Tepung di PT X. Jurnal Tirta, Vol. 01. No. 02.

[4] Sudana, A. A. K. Oka. 2007. Sistem Informasi Manajemen Inventori pada Perusahaan Layanan Jasaboga Pesawat Udara. Teknologi Elektro. Vol 06, No. 01.

[5] Stock, J.R. \& Lambert, D.M. 2001. Strategic Logistics Management, 4th ed. Singapore: Mc. Graw-Hill. 


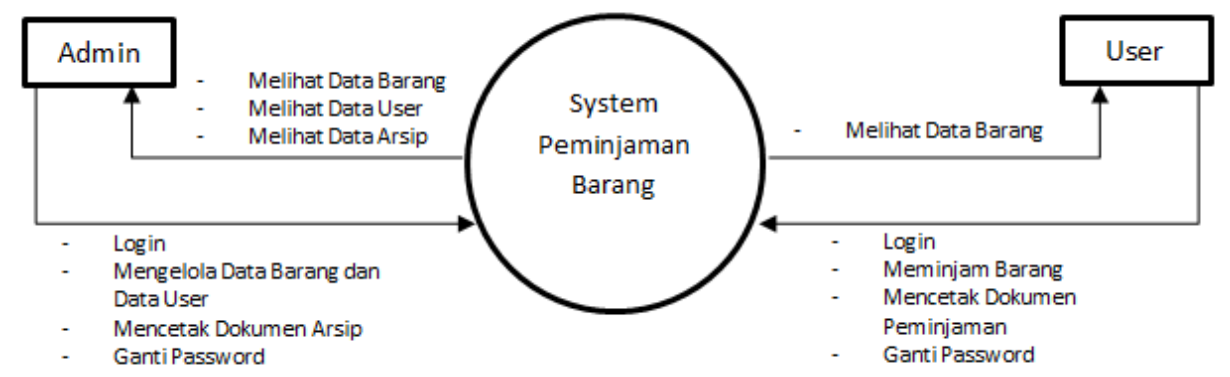

Gambar 1. Data flow diagram

\begin{tabular}{|ll|}
\hline & Admin \\
- & Kode Admin \\
- & Nama \\
& Admin \\
- & Username \\
\hline
\end{tabular}
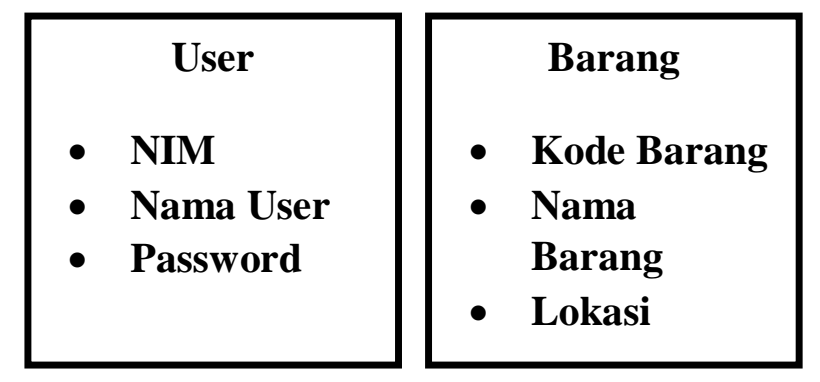

Gambar 2. Menentukan entitas

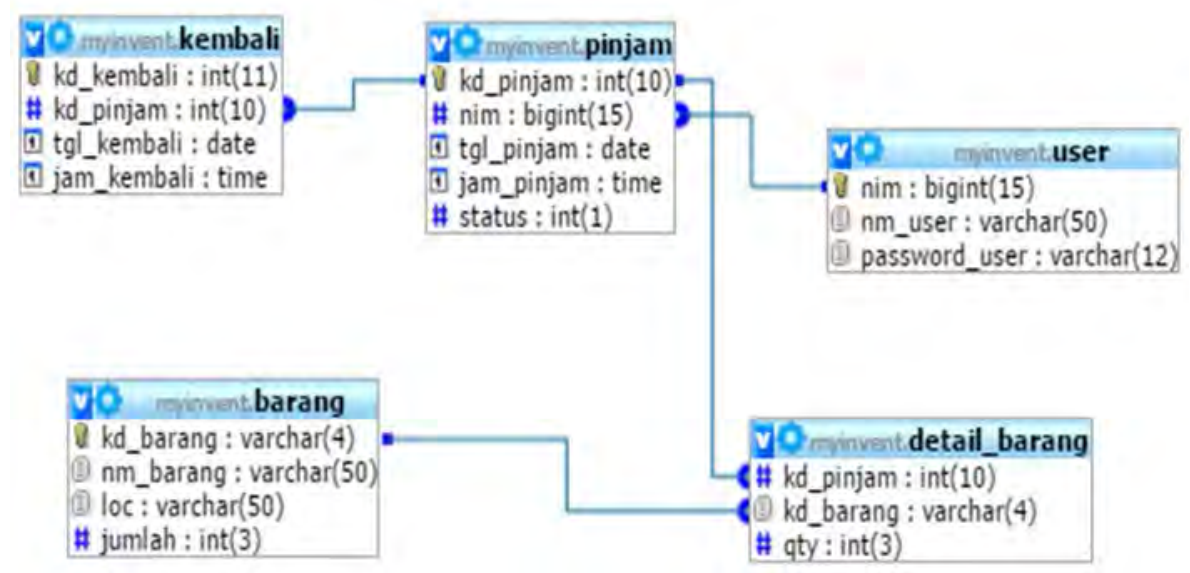

Gambar 3. Database dan relasi
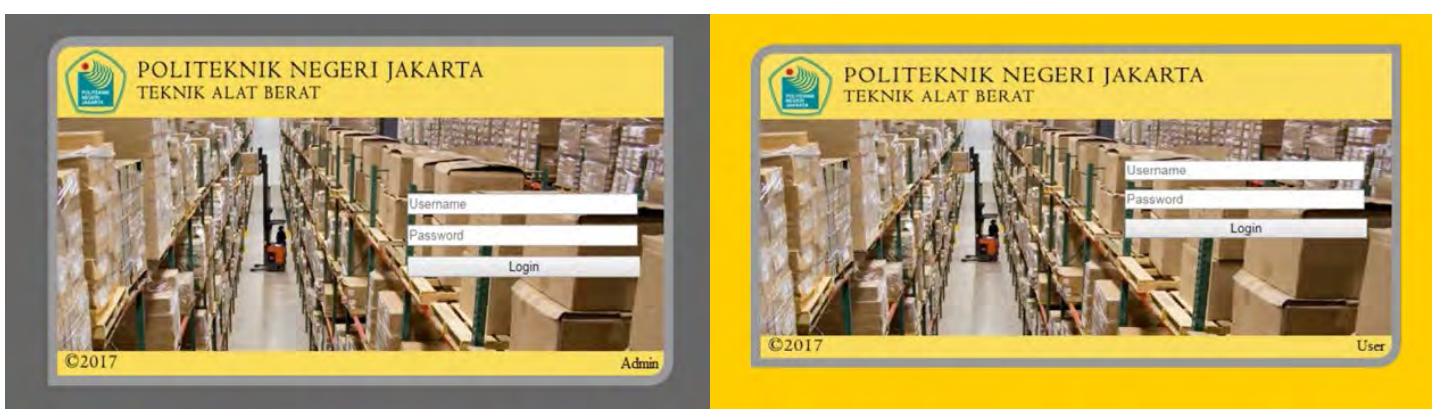

Gambar 4. Akun admin dan user 


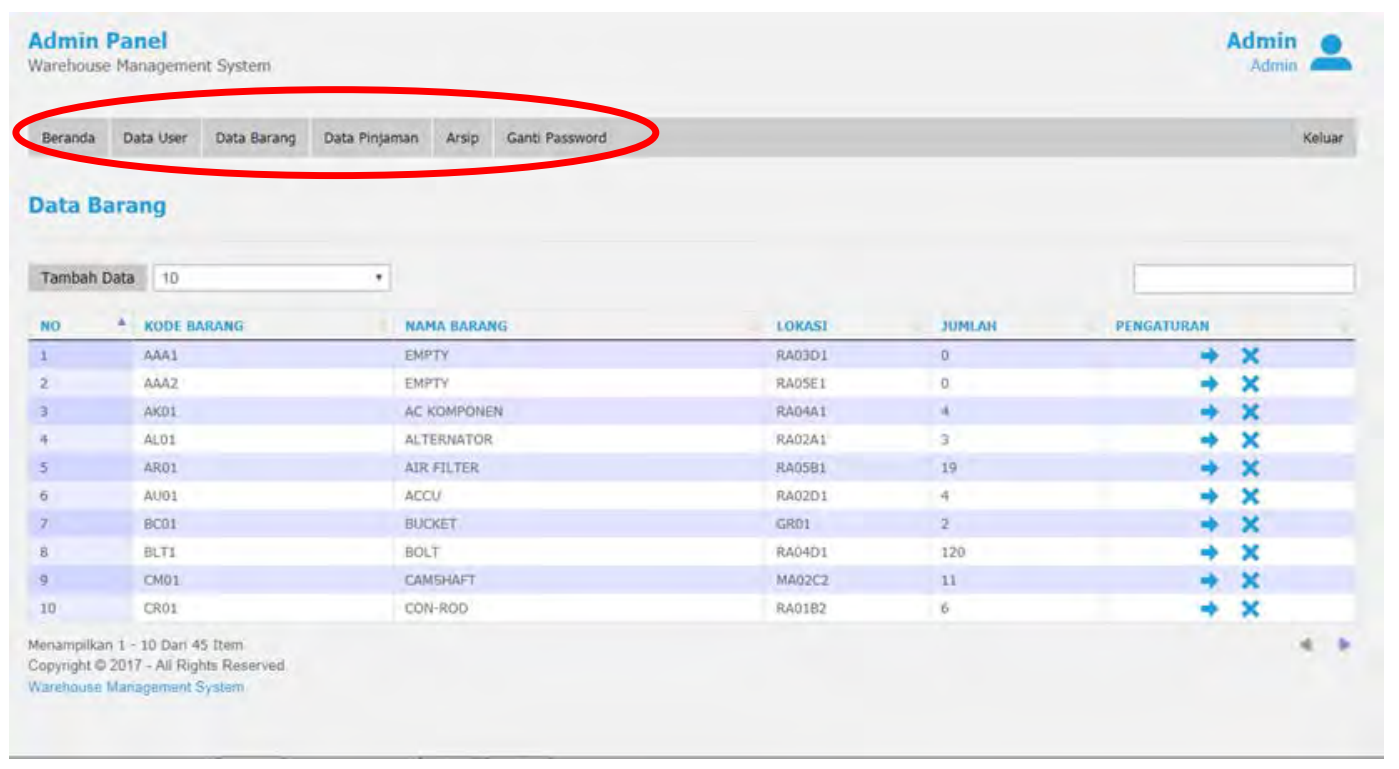

Gambar 5. Admin panel, menu beranda, menu data user, menu data barang, menu data pinjaman, menu arsip dan menu ganti password

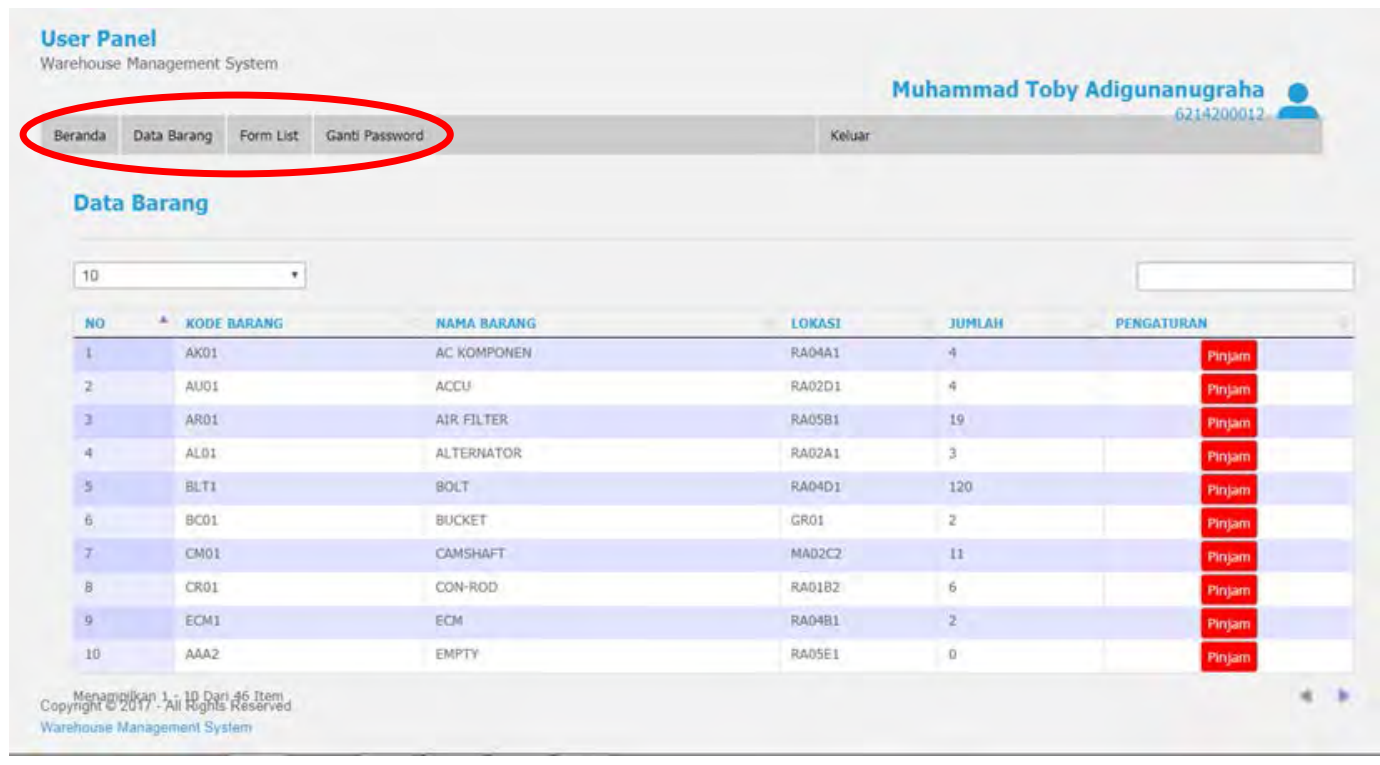

Gambar 6. User Panel, menu data barang, dan menu form list 
Abdul Azis A, Muhammad Toby A dan Ivana Bianca, Rancang Bangun Aplikasi... 